\title{
Trace element partitioning between clinopyroxene and alkali basaltic melts: investigation at high pressure on a composition from the Campi Flegrei Volcanic District (Italy)
}

\author{
Bonechi B. ${ }^{1 *}$, Perinelli C. ${ }^{1}$, GAETA M. ${ }^{1}$, FABbriziO \\ A. ${ }^{2}$, Petrelli M. ${ }^{3}$, StRnAd L. ${ }^{4}$ \\ ${ }^{1}$ Dipartimento di Scienze della Terra, Sapienza Università di \\ Roma, Italy \\ 2 Institute of Petrology and Structural Geology, Faculty of \\ Science, Charles University, Prague, Czech Republic \\ ${ }^{3}$ Department of Physics and Geology, University of Perugia, \\ Italy \\ ${ }^{4}$ Laboratories of the ageological Institutes, Faculty of Science, \\ Charles University, Prague, Czech Republic \\ (*correspondence: barbara.bonechi@uniromal.it)
}

Clinopyroxene is a common mineral and one of the most important constituents of igneous rocks. It has relatively high concentrations of most trace elements and it is, therefore, useful to study various processes including cooling rates, mantle melting, fractional crystallization and time scales of crystal residence in magma chambers. In this study, we present new experimental data on partition coefficients for trace elements between clinopyroxenes in equilibrium and in disequilibrium with a K-basaltic composition from Procida island (Campi Flegrei Volcanic District; CFVD). The experiments were carried out at $800 \mathrm{MPa}$ as a function of temperature (1080-1250 $\left.{ }^{\circ} \mathrm{C}\right)$ and time (0.25-9 hours). Moreover, for comparison we report the trace element concentrations of some natural clinopyroxene phenocrysts of some K-basaltic scoria clasts from Procida island. Variations of the partition coefficients were found as a function of the temperature, time, growth rate and the $\mathrm{Al}_{2} \mathrm{O}_{3}$ content in clinopyroxene. These variations are both positively and negatively correlated: for istance, $D_{\mathrm{Cr}}$ is positively correlated with time increasing from $\sim 5$ to $\sim 60$ with increasing time from 0.25 to $9 \mathrm{~h}$, while $D_{\text {Gd }}$ is negatively correlated decreasing from $\sim 1$ to $\sim 0.5$ with increasing time. Or even the variation with $\mathrm{Al}^{\mathrm{IV}}$ is positive for almost all $D$ except for $D_{\mathrm{Sr}}$ and $D_{\mathrm{Ba}}$ that instead decrease increasing $\mathrm{Al}^{\mathrm{IV}}$.

Finally, some representative trace elements were used to constrain the crystal residence times in the deep reservoir of the CFVD, obtaining estimates that are comparable with those available in literature for the Campi Flegrei. 